\title{
Effect of liquid glass type on hygienic characteristics of coated electrodes for arc welding of tin bronzes
}

\author{
Oleg Levchenko ${ }^{1}$, Olga Bezushko ${ }^{2}$, Taras Maidanchuk ${ }^{2}$, Anna Lukianenko ${ }^{2}$, Olga Goncharova ${ }^{2}$, Darko Bajic ${ }^{3}$, and \\ Darko Veljic ${ }^{4}$ \\ ${ }^{1}$ NTUU “Igor Sikorsky Kyiv Polytechnic Institute”, Kyiv, Ukraine \\ ${ }^{2}$ E.O. Paton Electric Welding Institute of the NASU, Kyiv, Ukraine \\ ${ }^{3}$ University of Montenegro, Faculty of Mechanical Engineering, Bul. Džordža Vašingtona bb, 81000 Podgorica, Montenegro \\ ${ }^{4}$ University of Belgrade, Innovation Center, Faculty of Technology and Metallurgy, 4 Karnegijeva Str., 11000 Belgrade, Serbia
}

\begin{abstract}
The results of investigations of chemical composition and emission rates of the welding fume, generated during welding using electrodes for copper alloys, are presented with the aim of improvement of their sanitary and hygienic characteristics. It is shown that in order to create new grades of welding electrodes with improved hygienic characteristics, it is necessary to have the data of the initial sanitary and hygienic evaluation in accordance with international standards. It was established that the use of binder based on pure lithium liquid glass in the coating of electrodes for welding copper alloys, increases the rate of welding fume emission into the air, as well as the content of manganese and copper oxides in it. The minimum rates of harmful emissions were recorded during the use of sodium-potassium binder, which is recommended for mass production of this type of electrodes.
\end{abstract}

\section{Introduction}

Manual arc welding of copper and copper alloys using coated electrodes is widely used in different industries, i.e. power engineering, metallurgy, foundry, etc. It is characterized by a number of harmful and hazardous factors that affect not only welder but also supporting personnel [1-3]. From a hygienic point of view, one of the most hazardous harmful factors is the presence of welding fume (WF) in the air, the toxic effect of which depends on the chemical composition of welding electrodes. The methodical standards DSTU ISO 15011-1:2008 [4] and DSTU ISO 15011-4:2008 [5] provide an opportunity to obtain the necessary information about the chemical composition of WF and approximately calculate the risk of their harmful effect on the body of welder.

\section{Processes of welding fume generation during manual arc welding of copper and its alloys}

A schematic view of the zone of manual arc welding is shown in Figure 1. Under the effect of the arc heat, at the end of the electrode a droplet of liquid metal is formed and growing, which is maintained by surface tension. Moreover, melting of the coating usually occurs little bit slower than melting of the electrode rod. As a result, a "casing" is formed, from which a partial evaporation of the coating materials and the metal melt occurs. A relatively small part of the metal evaporates as a result of a high boiling point of the metal and a significant heat of evaporation. A part of vapours is lost, getting into the atmosphere surrounding the arc, where the metal vapours condense into droplets, oxidize and transfer into fine solid particles of metal oxides, which form a fume and always surround the welding arc. [6].

\section{Classification of welding fume according to degree of harm}

During manual arc welding of tin bronzes, in the composition of WF such harmful substances as manganese, copper, their oxides and other components of welding material may be present. In all developed countries of the world, sanitary services control harmful substances in the air of the working area of production rooms for their compliance with the maximum allowable concentrations (MAC) according to special methodological standards. In particular, in Ukraine the MAC value for manganese, when its content in WF is lower than $20 \%$, amounts to $0.2 \mathrm{mg} / \mathrm{m}^{3}$, and when its content in WF starts from $20 \%$, it amounts to $0.1 \mathrm{mg} / \mathrm{m}^{3}$, the MAC of copper amounts to $1 \mathrm{mg} / \mathrm{m}^{3}$. These elements belong to the second category of hazard. They may cause inflammation of the mucous membrane, problems with the nervous system and fever of metal smoke. 


\section{Choice of material and procedure of experiments}

To investigate the rates of emissions and chemical composition of WF during manual arc welding of tin bronzes, the electrodes with a specific composition were used, which were developed at the E.O. Paton Electric Welding Institute [7]. Their composition is associated with the presence of chemically active substances related to the binder, such as liquid glass, components of sodium salts (hexafluorosilicate and hexafluoroaluminate), as well as non-traditional metal components (tin and copperphosphorus powders).

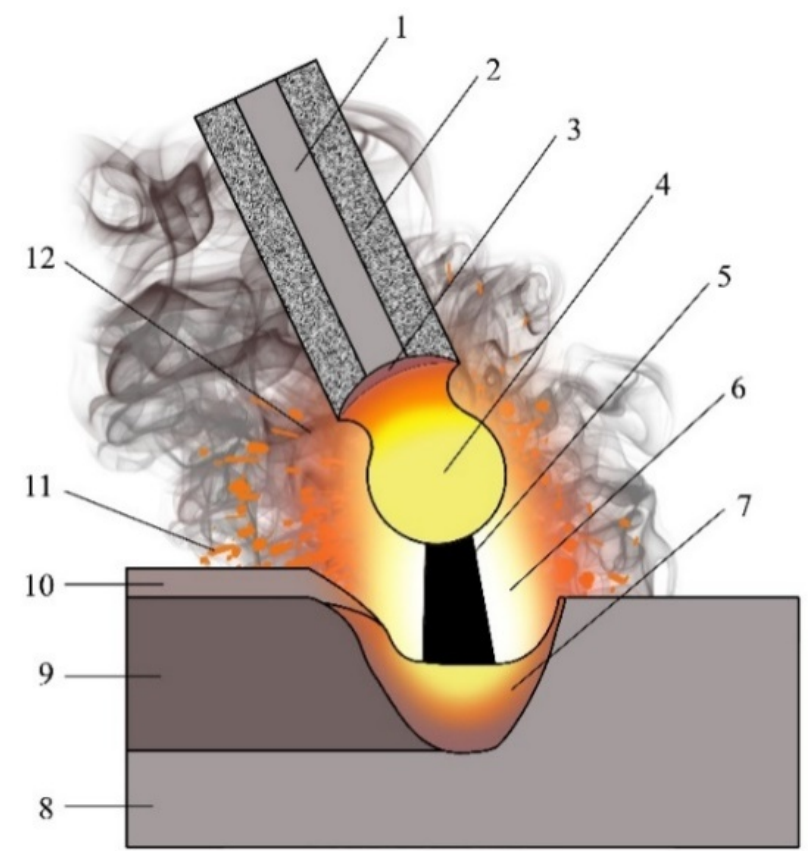

Fig. 1. Formation of welding fume: 1 - electrode rod; 2 electrode coating; 3 - molten electrode rod and coating; 4 droplet of electrode metal; 5 - arc column; 6 - arc flame; 7 welding pool; 8 - base metal; 9 - weld; 10 - slag; 11 - sparks (splashes) of liquid metal and slag; 12 - gases and welding fume

The main aim of the study is to choose the optimal type of alkaline silicate binder, the properties of which largely determine the manufacturing technology, quality, welding and sanitary properties of electrodes.For this purpose, standard (sodium, potassium and mixed sodium and potassium) [8] and experimental (lithium and lithiumcontaining) samples of liquid glass were prepared, which provide unique properties to some grades of electrodes
[9]. Their physicochemical characteristics are given in Table 1.

The experiments were performed on the electrodes, manufactured on copper rods, and a charge consisted of marble: cryolite, sodium silicon fluoride, tin, copperphosphorus, nickel and manganese powders [10]. For comparison, the mass-production electrodes OZB-2 and UTP-32 were also studied.

Sampling of WF for their dissolution is carried out in accordance with the standard [5] applying the method of complete capture of the fume, generated during welding with the use of the special bench with the FPP filter installed on a way of movement of WF from a shelter of a welding zone. The following indices of WF formation were determined: intensity of $\mathrm{V}_{\mathrm{a}}$ emission, $\mathrm{g} / \mathrm{min}$; specific emission of $\mathrm{G}_{\mathrm{a}}, \mathrm{g} / \mathrm{kg}$; chemical composition of WF, wt. \%. For each variant at least three experiments were performed. Welding was performed at direct current (150 A) of reverse polarity using VDU-504 rectifier.

\section{Results of investigations}

The welding conditions and general indices of welding fume emission are given in Table 2.

As the results of the investigations showed, the highest general values of intensity and specific emission of the welding fume were observed during welding using massproduced grades of electrodes UTP-32. Among the experimental electrodes, the highest values of $\mathrm{V}_{\mathrm{a}}$ and $\mathrm{Ga}$ were observed during welding using the electrodes with a binder based on lithium glass. The mass fraction of chemical elements in the welding fume during welding using mass-produced and experimental electrodes for welding tin bronzes is given in Table 3 .

According to the obtained results, the chemical composition of copper in the composition of WF does not differ significantly for all experimental grades of electrodes, whereas the intensity and specific emission are different (see Fig. 2-3). Moreover, the rate of emission of manganese differs both in chemical composition as well as intensity of its emission (see Fig.4-5). The lowest value of lithium among the experimental electrodes of grade ANBO with the content of lithium glass was obtained during welding using electrodes ANBO-Na-Li. Among the electrodes based on sodium glass, the highest value of sodium in WF was determined during welding using electrodes ANBO-Na. The content of potassium is the lowest in WF, obtained during welding using electrodes ANBO-Na.

Table 1. Physicochemical parameters of liquid types of glass [11]

\begin{tabular}{|c|c|c|c|c|c|c|c|}
\hline \multirow{2}{*}{ Type } & \multirow{2}{*}{$\begin{array}{l}\text { Density } \\
\rho, \mathrm{g} / \mathrm{cm}^{3}\end{array}$} & \multirow{2}{*}{$\begin{array}{c}\text { Toughness, } \\
\eta+20^{\circ} \mathrm{C} \text {, MPa·s }\end{array}$} & \multicolumn{4}{|c|}{ Chemical composition, wt. \% } & \multirow{2}{*}{ Module } \\
\hline & & & $\mathrm{SiO}_{2}$ & $\mathbf{L i}_{2} \mathbf{O}$ & $\mathrm{Na}_{2} \mathrm{O}$ & $\mathrm{K}_{2} \mathrm{O}$ & \\
\hline $\mathrm{Na}$ & 1.430 & 392 & 29.03 & - & 8.83 & 2.15 & 2.93 \\
\hline $\mathrm{Na}-\mathrm{K}$ & 1.435 & 606 & 28.80 & - & 6.94 & 4.56 & 2.99 \\
\hline $\mathrm{K}-\mathrm{Na}$ & 1.428 & 304 & 27.85 & - & 4.00 & 8.79 & 2.94 \\
\hline $\mathrm{K}$ & 1.415 & 260 & 26.92 & - & 0.03 & 13.78 & 3.05 \\
\hline $\mathrm{Na}-\mathrm{Li}$ & 1.396 & 526 & 30.19 & 2.69 & 0.99 & 5.17 & 2.73 \\
\hline K-Li & 1.421 & 554 & 27.93 & 1.42 & 0.94 & 10.67 & 2.65 \\
\hline $\mathrm{Li}$ & 1.258 & 287 & 25.08 & 3.19 & - & - & 3.91 \\
\hline
\end{tabular}


Table 2. Indices of emission rates of welding fume during welding of copper alloys

\begin{tabular}{|l|c|c|c|c|c|}
\hline \multicolumn{1}{|c|}{ Grade of electrode } & $\mathbf{I w}, \mathbf{A}$ & $\mathbf{U w}, \mathbf{V}$ & $\mathbf{g}, \mathbf{k g} / \mathbf{m i n}$ & $\mathbf{V}_{\mathbf{a}}, \mathbf{g} / \mathbf{m i n}$ & $\mathbf{G}_{\mathbf{a}}, \mathbf{g} / \mathbf{k g}$ \\
\hline OZB-2,mass-produced, 4 mm diameter & 120 & $24-28$ & 0.0430 & 0.3359 & 7.59 \\
\hline UTP-32,mass-produced, 3.2 mm diameter & 100 & 28 & 0.0336 & 0.7654 & 22.78 \\
\hline ANBO-Li, 4 mm diameter & 120 & 28 & 0.0447 & 0.4693 & 10.50 \\
\hline ANBO-Na, 4 mm diameter & 120 & 24 & 0.0413 & 0.3006 & 7.28 \\
\hline ANBO-K, 4 mm diameter & 120 & 24 & 0.0366 & 0.3010 & 8.22 \\
\hline ANBO-Na-Li, 4 mm diameter & 120 & 24 & 0.0380 & 0.2594 & 6.82 \\
\hline ANBO-K-Li, 4 mm diameter & 120 & 24 & 0.0396 & 0.3948 & 9.97 \\
\hline ANBO-K-Na, 4 mm diameter & 120 & 24 & 0.0304 & 0.2874 & 9.45 \\
\hline
\end{tabular}

Table 3. Mass fraction of chemical elements in the welding fume.

\begin{tabular}{|l|c|c|c|c|c|}
\hline \multirow{2}{*}{\multicolumn{1}{|c|}{ Grade of electrode }} & \multicolumn{5}{|c|}{ Mass fraction in WF, \% } \\
\cline { 2 - 6 } & $\mathbf{C u}$ & $\mathbf{M n}$ & $\mathbf{L i}$ & $\mathbf{N a}$ & $\mathbf{K}$ \\
\hline OZB-2,mass-produced, 4 mm diameter & 35.50 & 1.56 & - & - & - \\
\hline UTP-32,mass-produced, 3.2 mm diameter & 36.78 & 2.93 & - & - & - \\
\hline ANBO-Li, 4 mm diameter & 33.38 & 3.16 & 0.82 & - & - \\
\hline ANBO-Na, 4 mm diameter & 33.42 & 2.50 & - & 9.14 & - \\
\hline ANBO-K, 4 mm diameter & 33.35 & 2.40 & - & - & 13.15 \\
\hline ANBO-Na-Li, 4 mm diameter & 33.49 & 2.81 & 0.68 & 7.57 & - \\
\hline ANBO-K-Li, 4 mm diameter & 33.33 & 2.41 & 0.85 & - & 9.06 \\
\hline ANBO-K-Na, 4 mm diameter & 33.26 & 1.95 & - & 7.82 & 12.34 \\
\hline
\end{tabular}

The obtained results clearly show that the highest values of specific emission and intensity of WF formation were determined during welding using mass-produced grades of electrodes UTP-32 and experimental electrodes ANBO-Li.

To determine the final estimated indices of hygienic evaluation of welding materials in compliance with the standard DSTU ISO 15011-4: 2008, the limit value of the welding fume was determined by the following equation:

$$
L V_{W F(A)}=\frac{100}{\sum_{1}^{n} \frac{i}{L V_{i}}+\frac{\left(100-\sum_{1}^{n} i\right)}{L V_{W F}}}
$$

where $L V_{\mathrm{WF}(\mathrm{A})}$ is the total limit value of the welding fume, in $\mathrm{mg} / \mathrm{m}^{3} ; n$ is the number of main components of the welding fume; $i$ is the fraction of $i$-th main component of the welding fume in $\%$; $L i$ is the limit value (MAC) in $\mathrm{mg} / \mathrm{m}^{3}$ for $i$-th main component of the welding fume; $L V_{W F}$ is the limit value in $\mathrm{mg} / \mathrm{m}^{3}$ for the welding fume, which contains chemicals with a low and medium toxicity, if such a limit was established, or a limit value in $\mathrm{mg} / \mathrm{m}^{3}$ for inhaled dust, if no limit value for the welding fume was established.

Due to the fact that the procedure [12] does not allow determining the content of all components of WF to bring its composition to $100 \%$, it was assumed that in addition to the revealed components, the residue of WF represents a non-toxic dust with MAC of $10 \mathrm{mg} / \mathrm{m}^{3}$. The results of the calculation are shown in Table 4.

Regarding the hygienic category of all test specimens of welding electrodes according to DSTU ISO 15011-4: 2008 , determined by the formula 1 , all of them belong to a one category $1 \mathrm{~b}$, except for the electrodes UTP-32, which belong to the category $1 \mathrm{c}$ (Table 4). It implies a harmful category "1" according to the limit value of WF (from 0.5 to $1.5 \mathrm{mg} / \mathrm{m}^{3}$ ) and a moderate category "c" as to the level of its emissions (from 8 to $15 \mathrm{mg} / \mathrm{s}$ ).

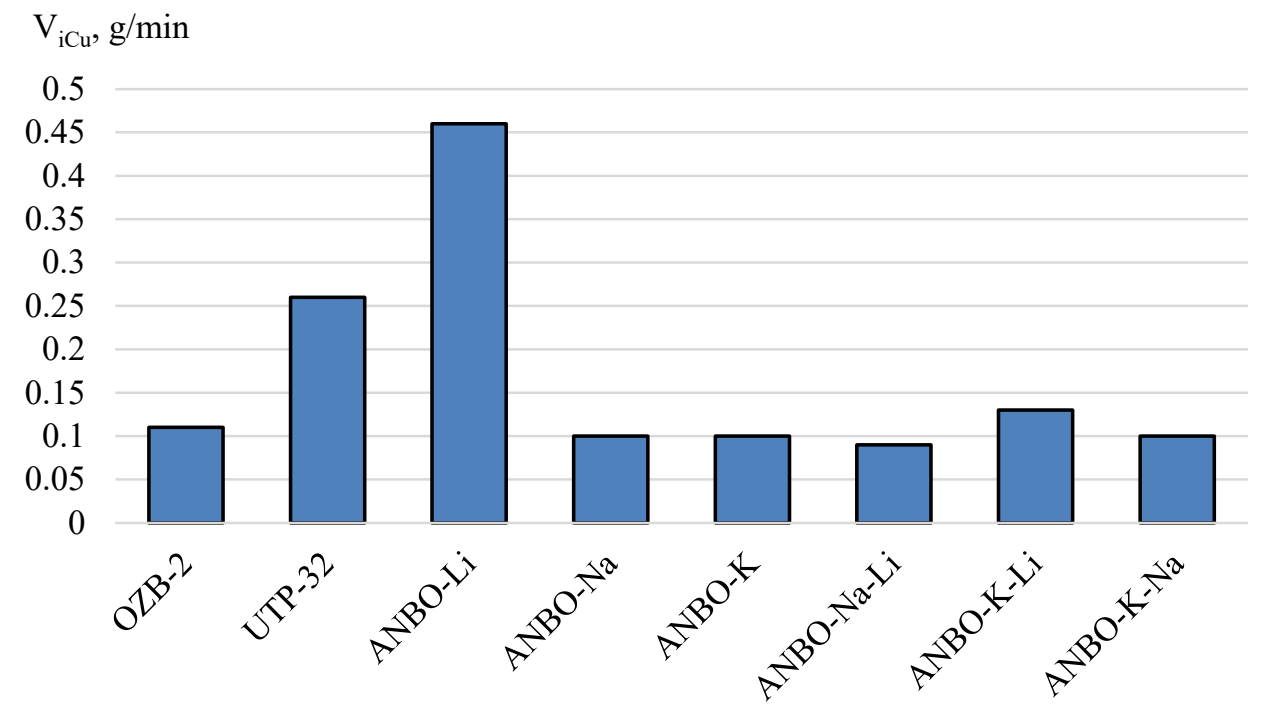

Fig. 2. Intensity of copper formation in the composition of WF. 


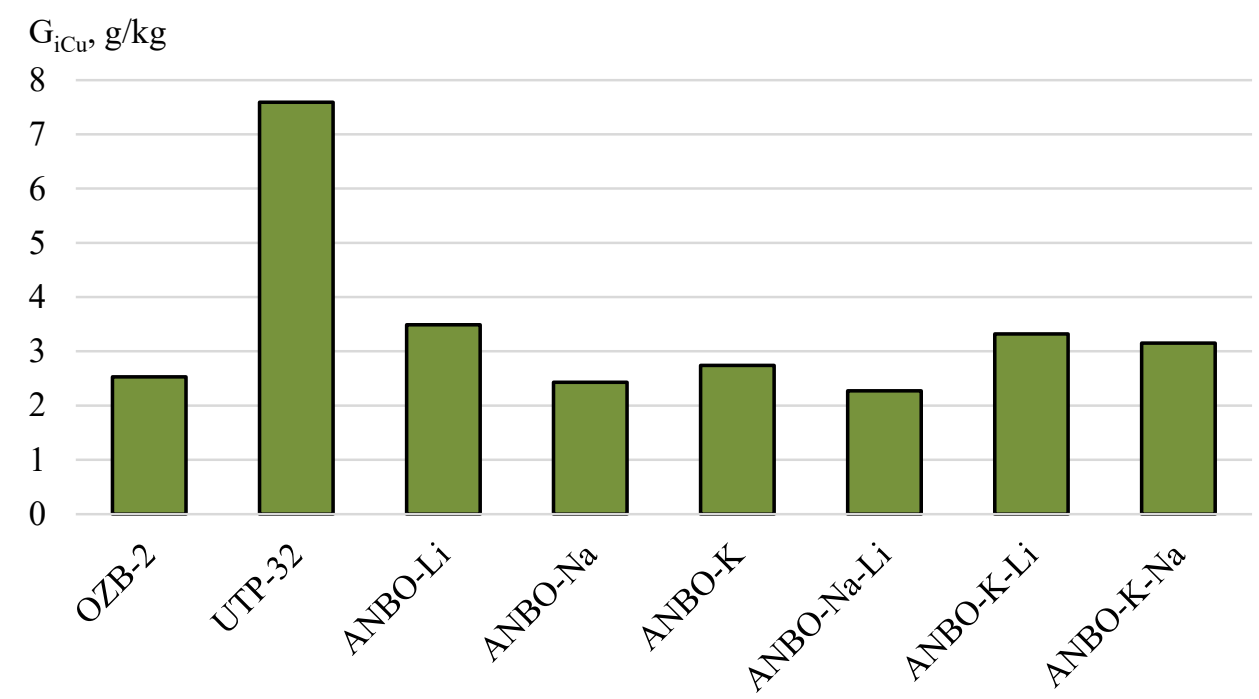

Fig. 3. Specific emission of copper in the composition of WF.

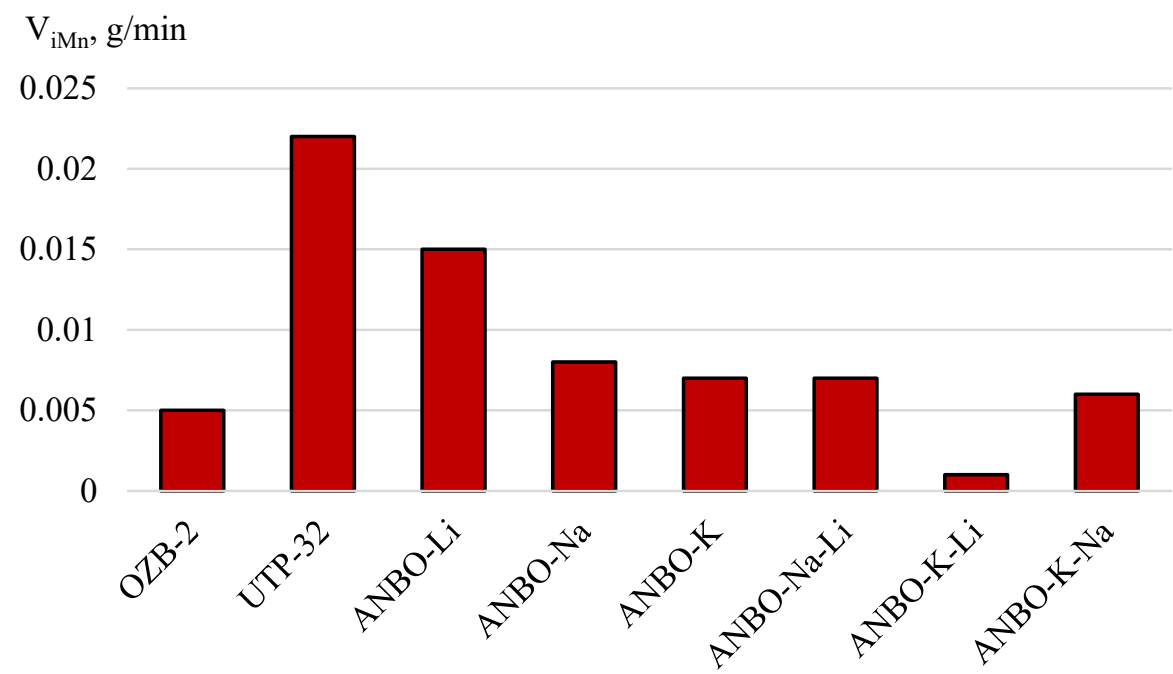

Fig. 4. Intensity of manganese formation in the composition of WF.

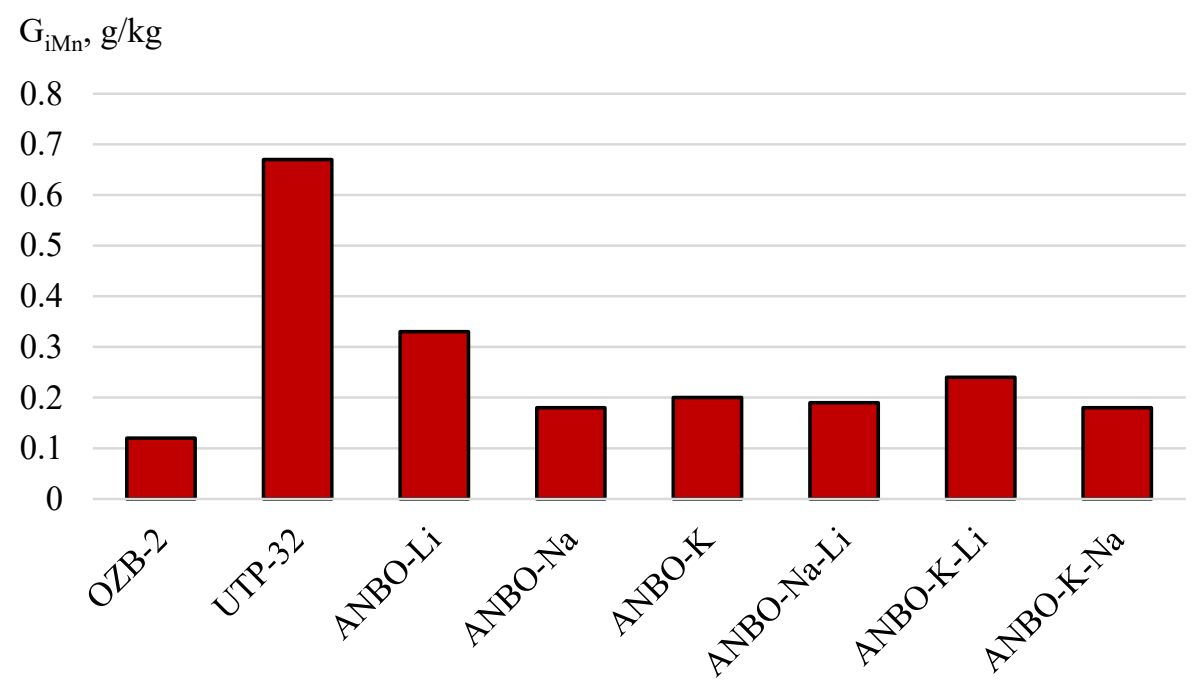

Fig. 5. Specific emission of manganese in the composition of WF. 
Comparing the electrodes according to the total limit value of the welding fume, which is an index of toxicity, the most harmful grade of electrodes will be ANBO-Li, followed by mass-produced grades UTP-32 and ANBONa-Li.

As a result of investigations with the use of electrodes for welding tin bronzes, a high intensity of the welding fume emission was established, that is explained by existence of volatile compounds and a high basicity of a slag phase in the coating.

The performed analyses show that the basis of WF consists of such components as compounds of alkali and alkaline earth metals $\left(\mathrm{Na}_{2} \mathrm{O} ; \mathrm{K}_{2} \mathrm{O} ; \mathrm{Li}_{2} \mathrm{O}\right)$, copper, manganese, etc. As to the total limit value of the welding fume, among the experimental electrodes, WF emissions are the least toxic during welding using electrodes ANBO-K-Na. During welding using electrodes made of potassium-sodium glass, the highest indices of weldingtechnological characteristics were also established [12]. Therefore, during the subsequent experiments the electrodes were used made on the basis of potassiumsodium type of glass, which were given the index EOF50.

\section{Methods of reducing emissions of harmful WF components into the working area during manual arc welding of tin bronzes}

Reducing the harmful effect of welding fume on the body is fulfilled by the use of technological and sanitarytechnical measures, as well as the use of means of individual protection $[13,14,15]$. A particular interest of developers of welding materials and technologies is attracted to technological methods of reducing the rate of WF emission, which are aimed in improvement of welding materials, technologies and equipment in terms of hygienic protection and selection of optimal welding conditions.

The carried out investigations on the effect of a type of electrode coating on hygienic characteristics of welding fume may be based on the calculation of the value of a required intensity of ventilation air exchange, which is denoted as NHL and expressed in $\mathrm{m}^{3} / \mathrm{min}$ [16].

The further investigations were performed in accordance with the international standard DSTU ISO 15011-4:2008 using $L V_{\mathrm{WF}(\mathrm{A})}$ indices (see equation 1), category of welding material, intensity of WF emission, as well as $N H L$.

The results of NHL calculation are shown in Table 5.

The worst values according to the $L V_{\mathrm{WF}(\mathrm{A})}$ index were noted during welding using electrodes ANBO-Li, although not all experimental electrodes differ significantly as to the limit value, whereas $N H L$ for electrodes UTP-32 one and a half times increases. As to the totality of these changes, in this case an increase in the degree of a harmful effect of WF on a human by about 1.5 times can be reported.

\section{Conclusions}

The main method to improve hygienic characteristics of welding materials is certainly a change in the chemical composition of welding material. This task is not easy, because the main requirement of the welding process is to provide a high quality and the required mechanical properties of a weld. Therefore, welding materials always contain toxic chemicals, without which it is impossible to provide the necessary properties of welded joints. However, some improvements in hygienic characteristics of welding materials (minimization of harmful emissions) can be achieved.

Table 4. Indices of hygienic evaluation of welding materials determined by the calculation method in accordance with the standard DSTU ISO 15011-4: 2008.

\begin{tabular}{|l|c|c|c|}
\hline \multicolumn{1}{|c|}{ Grade of electrode } & $\mathbf{V}_{\mathbf{a}}, \mathbf{~ m g} / \mathbf{s}$ & $\boldsymbol{L} \boldsymbol{V}_{\mathbf{W F}(\mathbf{A}), \mathbf{~ m g} / \mathbf{m}^{3}}$ & Category of electrode \\
\hline OZB-2,mass-produced, 4 mm diameter & 5.598 & 1.059 & $1 \mathrm{~b}$ \\
\hline UTP-32,mass-produced, 3.2 mm diameter & 12.757 & 0.989 & $1 \mathrm{c}$ \\
\hline ANBO-Li, 4 mm diameter & 7.8217 & 0.978 & $1 \mathrm{~b}$ \\
\hline ANBO-Na, 4 mm diameter & 5.01 & 1.01 & $1 \mathrm{~b}$ \\
\hline ANBO-K, 4 mm diameter & 5.017 & 1.015 & $1 \mathrm{~b}$ \\
\hline ANBO-Na-Li, 4 mm diameter & 4.323 & 0.994 & $1 \mathrm{~b}$ \\
\hline ANBO-K-Li, 4 mm diameter & 6.58 & 1.014 & $1 \mathrm{~b}$ \\
\hline ANBO-K-Na, 4 mm diameter & 4.79 & 1.038 & $1 \mathrm{~b}$ \\
\hline
\end{tabular}

Table 5. Hygienic indices of WF emissions during welding of copper alloys using experimental electrodes.

\begin{tabular}{|l|c|c|c|}
\hline Grade of electrode & $\mathbf{V a , g} / \mathbf{m i n}$ & $\mathbf{L} \boldsymbol{V}_{\mathbf{W F}(\mathbf{A}), \mathbf{g} / \mathbf{m}^{\mathbf{3}}}$ & $\mathbf{N H L}, \mathbf{~ m}^{\mathbf{3}} / \mathbf{m i n}$ \\
\hline OZB-2,mass-produced, 4 mm diameter & 0.3359 & $1.059 \cdot 10^{-3}$ & 317.186 \\
\hline UTP-32,mass-produced, 3.2 mm diameter & 0.7654 & $0.989 \cdot 10^{-3}$ & 773.913 \\
\hline ANBO-Li, 4 mm diameter & 0.4693 & $0.978 \cdot 10^{-3}$ & 479.8569 \\
\hline ANBO-Na, 4 mm diameter & 0.3006 & $1.01 \cdot 10^{-3}$ & 297.6238 \\
\hline ANBO-K, 4 mm diameter & 0.3010 & $1.015 \cdot 10^{-3}$ & 296.5517 \\
\hline ANBO-Na-Li, 4 mm diameter & 0.2594 & $0.994 \cdot 10^{-3}$ & 260.9658 \\
\hline ANBO-K-Li, 4 mm diameter & 0.3948 & $1.014 \cdot 10^{-3}$ & 389.3491 \\
\hline ANBO-K-Na, 4 mm diameter & 0.2874 & $1.038 \cdot 10^{-3}$ & 276.8786 \\
\hline
\end{tabular}


The emission rates and chemical composition of WF are determined by the content of chemical elements or compounds in welding electrodes. As a result of melting the coating and the electrode rod, at the end of the electrode evaporation of elements with a high vapour pressure occurs. One of the most harmful substances contained in WF, generated during welding of tin bronzes, are compounds of manganese and copper.

The analysis of the obtained results of the investigations and literature data allowed concluding that to provide the maximum improvement in hygienic characteristics of welding materials, it is necessary to be guided by a comprehensive approach. To minimize the harmful properties of WF and its effect on the body, it is necessary to choose the optimal combination of the following technological methods for reducing the rate of harmful substances emission:

1. If possible, it is necessary to use those types and grades of welding materials that provide a reduced level of WF emissions.

2. Taking into account hygienic characteristics while choosing electrodes for welding copper alloys, between the grades ANBO and UTP-32 the preference should be given to the first one. As far as during the use of the electrodes of experimental grades ANBO with a different type of binder, the specific WF emissions are 1.7-3.0 times lower as compared to the mass-produced grade UTP-32.

3. The obtained results of the carried out investigations can be used during calculation of the systems for mechanical ventilation: determination of amount of air $\mathrm{L}$ $\left(\mathrm{m}^{3} / \mathrm{h}\right)$ which needs to be supplied or removed from the room. To calculate the ventilation of production rooms where welding is used, air exchange is required, which is usually determined by the calculation method based on specified data on the amount of harmful substances emissions.

\section{References}

1. K.Yu. Kirichenko, A. I.Agoshkov, V.A. Drozd, A.V.Gridasov, A. S. Kholodov, S. P. Kobylyakov, K. S.Golokhvast. Characterization of fume particles generated during arc welding with various covered electrodes. Scientific reports 8: 17169 (2018) doi:10.1038/s41598-018-35494-1

2. BY L. G. Cena, B. T. Chen, M. J. Keane. Evolution of welding fume aerosols with time and distance from the source. Welding journal VOL. 95, 280-285 (2016)

3. D P Il'yaschenko, D A Chinakhov, K V Ivanov, I D Sadikov. Improving hygienic characteristics of coated electrodes for welding high-alloy steels. Ecology and safety in the technosphere: current problems and solutions IOP Publishing. IOP Conf. Series: Earth and Environmental Science 50: $012047 \quad$ (2017) doi:10.1088/1755-1315/50/1/012047

4. DSTU ISO 15011-1:2008. Health and safety in welding and allied processes. Laboratory method for sampling fume and gases generated by arc welding. Part 1: Determination of fume emission rate and sampling of fume microparticles for analysis [Valid from 2008-08-15]. Kyiv, Derzhspozhyvstandart of Ukraine, 2011, 8 p.

5. DSTU ISO 15011-4:2008. Health and safety in welding and allied processes. Laboratory method for sampling fume and gases. Part 4: Fume data sheets. [Valid from 2008-08-15]. Kyiv, Derzhspozhyvstandart of Ukraine, 2011, 20 p.

6. Levchenko O.G., Bezushko O.M. Minimization of welding fumes emissions. NTUU "Igor Sikorsky KPI”. GlobeEdit, 150 (2020). ISBN: 978-620-059869-1(published in Ukrainian language)

7. Zaks I.A. Electrodes for arc welding of non-ferrous metals and alloys: Reference manual. St. Petersburg. Stroyizdat Sankt-Peterburg 192 (1999).

8. Sidlin Z.A. Production of electrodes for manual arc welding. Kyiv, Ekotekhnologiya, 464 (2009).

9. Skoryna N.V., Kisilyov M.O., Paltsevich A.P., Levchenko O.G. Properties of lithium-containing liquid glasses for production of welding electrodes. Proceedings of the IV International Conference on Welding Materials of the CIS countries. Krasnodar,75-82 (2011).

10. P.O. Box No.106954 UA, V23K 35/365(2006.01). Electrode coating composition for welding and surfacing of tin bronzes. Ilyushenko V.M., Maidanchuk T.B., Anoshyn V.O., Skoryna M.V. - №a 2013 14841; Appl. of 18.12.2013; Publ. on 10/27/2014 Bull. №20

11. Maidanchuk T.B., Skoryna N.V. Improvement of manufacturability and welding properties of electrodes for welding and surfacing of tin bronzes. Avtomaticheskaya svarka 6-7, 176-181 (2014). ISSN:0005-111X

12. Kireev V.I., Mosolov N.I., Golovatyuk A.P., Suprun S.A., Hygienic evaluation of air environment during welding works. Methods for evaluation of production environment at industrial enterprises. Moscow, Meditsina. 91-100 (1980).

13. O.G. Levchenko. Work safety in the welding industry: Education manual. Kyiv, Osnova. 240 (2010).

14. Levchenko O.G. Welding fumes and gases: generation processes, neutralization methods and means of protection. Kyiv, Naukova dumka, 248 (2015).

15. Levchenko O.G. Improvement of methods and means of protection against welding fumes. Avtomat. svarka, 3, 9-16 (2003).

16. Pokhodnya I.K., Yavdoshchin I.R., Gubenya I.P. Welding fume - factors of effect, physical properties, methods of analysis (Review) Avtomaticheskaya svarka, 6, 39-42 (2011). 